\title{
Manuel de Jesús Galván oder der Edle Wilde auf den Antillen
}

An dieser Stelle unserer Vorlesung böte sich die verlockende Möglichkeit an, $\mathrm{zu}$ Jorge Isaacs und einem der berühmtesten romantischen Romane Lateinamerikas überzuwechseln, um damit die Karibik hinter uns zu lassen. Doch habe ich mich mit Isaacs Roman María und seiner amerikanischen Implementierung und Transformation europäischer Vorbilder, welche insbesondere der Feder Chateaubriands entstammen, bereits in einer anderen Vorlesung ausführlich gewidmet und will darauf nicht zurückkommen. Denn María gilt mit Recht als eine jener Romanschöpfungen, in welchen die romantische Liebe am intensivsten mit der gemeinsamen Lektüre und folglich mit dem Motiv des LiebeLesens im Sinne von Dantes Paolo und Francesca verbunden ist. ${ }^{1}$ Die Komplexität literarischer wie kultureller Verhältnisse ist im inselkaribischen Raum jedoch bereits im spanischsprachigen Bereich so hoch, dass es mir klüger scheint, an dieser Stelle lediglich auf die Analyse dieses kolumbianischen und zugleich dem andinen Raum entstammenden Roman zu verweisen. Vielmehr wollen wir uns auf zwei karibische Autoren konzentrieren, die unser Bild karibischer Insel-Welten und Inselwelten im 19. Jahrhundert abrunden sollen!

Dem dominikanischen Autor Manuel de Jesús Galván, in Santo Domingo am 19. Januar 1834 geboren und in San Juan de Puerto Rico am 13. Dezember 1910 gestorben, gelang das, was sich jeder im Grunde zweitklassige Schriftsteller einmal in seinem Leben erträumt: den ganz großen literarischen Coup zu landen. Er schaffte dies mit dem umfangreichen, in drei Teilen mit insgesamt einhundertfünfundzwanzig Kapiteln reich untergliederten Roman Enriquillo, der erstmals 1879 erschien, in einer vollständigen und definitiven Fassung aber erst 1882 vorlag. ${ }^{2}$

Manuel de Jesús Galván, der außerhalb dominikanischer und mit der dominikanischen Nationalliteratur vertrauter Zirkel heute nur wenigen noch bekannt ist, war früh schon innerhalb der Literaturszene der jungen Dominikanischen Republik aktiv geworden, hatte bei Zeitschriften- und Literatenvereinigungen mitgewirkt, ohne freilich durch seine dichterischen Schöpfungen in besonderer

1 Vgl. das Kapitel „Jorge Isaacs, Liebe, Lesen und eine krank machende Lektüre“ in Ette, Ottmar: LiebeLesen, S. 529-551 im zweiten Band dieser „Aula“-Reihe.

2 Vgl. Varela Jácome, Benito: Evolución de la novela Hispanoamericana en el XIX. In Iñigo Madrigal, Luis (Hg.): Historia de la literatura hispanoamericana. Bd. II: Del neoclasicismo al modernismo. Madrid: Ediciones Cátedra 1987, S. 91-133; sowie Altman, Ida: The Revolt of Enriquillo and the Historiography of Early Spanish America. In: The Americas LXIII, 4 (2007), S. 587-614. 


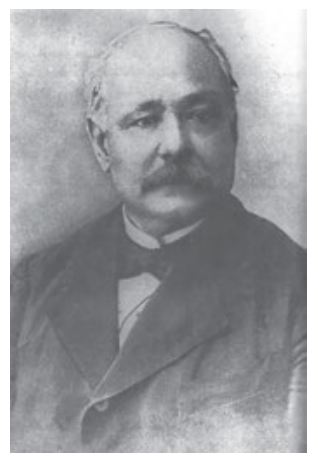

Abb. 57: Manuel de Jesús Galván (Santo Domingo, Dominikanische Republik, 1834 - San Juan, Puerto Rico, 1910).

Weise hervorzutreten. Sein Roman, so ließe sich formulieren, stellt eine späte, zugleich aber auch reife Frucht der hispanoamerikanischen Romantik dar.

Fungiert die Romantik - wie wir bereits verschiedentlich sahen - in Lateinamerika als Sattelzeit der jeweiligen Nationalliteraturen par excellence, so ist der von Manuel de Jesús Galván geschaffene Roman von 1882 gerade dies: ein Begründungstext dominikanischer Nationalität und Nationalliteratur, die ihre Spuren außerhalb der rein hispanisch vorgegebenen Identitätsmuster zu finden suchte. Ort und Zeitraum dieser Suche ist gerade nicht der komplizierte, von grundlegenden Widersprüchen durchzogene Prozess der Abtrennung vom spanischen Mutterland seit Ende des 18. und Beginn des 19. Jahrhunderts, sondern jener der spanischen Eroberung und Beseitigung der indigenen, der autochthonen Kulturen am Ende des 15. und zu Beginn des 16. Jahrhunderts. Es handelt sich um geschichtliche Ereignisse, wie sie neben anderen spanischen Chronisten der Dominikaner Bartolomé de las Casas in seiner Historia de las Indias brillant darzustellen vermocht hatte. Dessen Geschichte ist daher auch einer der wichtigsten Intertexte dieses Historischen Romans.

Dieser kann und muss als nationenstiftende und -begründende literarische Gattung aufgefasst werden; und diese Funktion hat keineswegs erst die spätere Forschung herausgestellt. Sie war schon den Zeitgenossen höchst bewusst und wurde von einigen der großen Vertreter hispanoamerikanischer Romantik programmatisch formuliert. Gerade in Ermangelung einer ausgebildeten Geschichtswissenschaft übernahm der Roman Aufgaben, wie sie in Europa insbesondere der Historiographie zuzufallen pflegten.

So findet sich insbesondere bei Bartolomé Mitre, dem berühmten argentinischen Historiker, dem späteren General und Präsidenten Argentiniens, bereits in einem Text von 1847 - also noch Jahre vor der Veröffentlichung von José Mármols Amalia - explizit die Einforderung einer solchen Funktion, die der argentinische Autor gleich selbst in seinem Roman Soledad (dem der Text später als Vorwort 


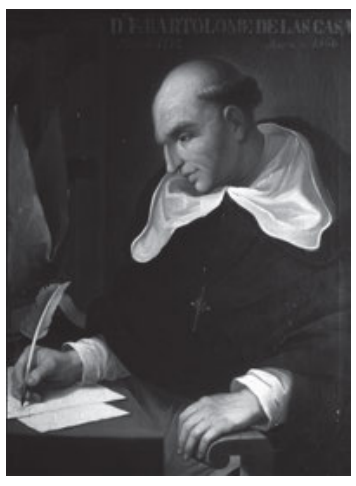

Abb. 58: Bartolomé de las Casas (Sevilla, 1484 oder 1485 Madrid, 1566).

diente) zu verwirklichen suchte. Ausgehend von der polemischen Feststellung, dass Südamerika hinsichtlich der Romanciers die ärmste Region der Welt sei, vertrat Bartolomé Mitre die These, dass eine Serie guter Romane substantiell die politische und soziale Reife der amerikanischen Länder anheben werde: eine klare didaktische Zielsetzung, welche der Literatur wichtige gesellschaftliche Funktionen übertrug. Sein eigener Roman - so schloss Mitre sein literarisch-politisches Manifest $a b^{3}$ - solle lediglich dazu dienen, weitere Romane zu stimulieren, die diesen hohen Ansprüchen genügen könnten.

Dies waren fürwahr beeindruckende Worte aus dem Munde eines argentinischen Historikers; und es ließe sich sehr wohl sagen, dass Bartolomé Mitre hier der Literatur und insbesondere der Romankunst eine wesentlich tiefere und weitergehende gesellschaftliche Wirkung zuschrieb als der von ihm selbst praktizierten Geschichtsschreibung. Auf diese Weise sollte aus der Not der Geschichtsschreibung die Tugend der Literatur werden. Manuel de Jesús Galván, der über seine journalistischen Tätigkeiten hinaus auch politische Ambitionen besaß, hat derlei Überlegungen in seiner Heimat in die Tat umgesetzt. Er war sicherlich nicht der erste, der dies versuchte, aber gewiss der erfolgreichste. Da muss die Frage erlaubt sein, was diesen Erfolg entscheidend begünstigte!

$\mathrm{Zu}$ ihrer Beantwortung müssen wir etwas ausholen und wichtige Elemente dieses recht umfangreichen Romans genauer untersuchen, der unter dem vollständigen Titel Enriquillo. Leyenda Histórica Dominicana (1503-1538) erschien.

3 Vgl. hierzu Sommer, Doris: Not Just Any Narrative: How Romance Can Love Us To Death. In: Balderston, Daniel (Hg.): The Historical Novel in Latin America. A Symposium. Gaithersburg: Ediciones Hispamérica 1986, S. 47-73, hier S. 50. 
Schon in diesem definitiven Titel von 1882 gibt der Text ebenso die Ebene der erzählten Zeit und den Bezugsraum (die Romandiegese) bekannt, wie auch die Angabe der gewählten literarischen Gattung, welche sich freilich in der Formulierung Leyenda histórica als historische Legende recht ambivalent darstellt. Denn im selben Atemzug wird der fiktionale Status als „Leyenda“ und damit das Legendenhafte wie der realitätsbezogen-mimetische und faktentreue Status des Historischen behauptet. Genau innerhalb dieser hier ausgesteckten Ambivalenz siedelt sich der Historische Roman - wie wir ihn weiter nennen wollen - von Manuel de Jesús Galván an.

Der kubanische Dichter und Literaturkritiker José Martí, der in einem berühmt gewordenen Brief vom 19. September 1884, welcher bis heute nahezu allen Ausgaben Enriquillos vorangestellt wird, die Qualitäten des Romans hervorhob, scheint keinen Gefallen an der Selbstbezeichnung als Leyenda histórica gefunden zu haben und definierte den Text lieber als absolut neue Form, „unsere amerikanische Geschichte zu schreiben“. Damit verschob er die Gewichte eher in den Bereich der Historiographie, vermutlich mit dem Hintergedanken, dass auf diese Weise der romaneske Text seine literarische und nationalitätsschaffende Funktion besser ausspielen und umsetzen können würde.

Im Übrigen ließ er keinen Zweifel daran, dass es Galván gelungen sei, in einem einzigen Werk Roman, Gedicht und Geschichte miteinander zu verbinden, um etwas Großes zu schaffen. Kommen wir aber nun zum Text selbst und beginnen wir mit seinem Incipit:

Der Name Jaragua glänzt auf den ersten Seiten der Geschichte Amerikas mit demselben Prestige wie zu antiken Zeiten in den mythologischen Erzählungen über das unschuldige Arkadien, die güldenen Hesperiden, das wunderschöne Tal von Tempé oder andere bevorzugte Gebiete unseres Erdkreises, die von der Natur mit allen Verzauberungen ausgestattet wurden, welche die Einbildungskraft verführen und mit entzückenden Chimären bevölkern. Ihnen gleicht das indianische Königreich von Jaragua und erscheint vor den modernen Argonauten, die zu seiner Eroberung auszogen, wie eine wunderbare Region, reich und glücklich. Von einer schönen und liebreizenden Königin regiert; von einer gütigen Rasse von klarem Verständnis und anmutigen physischen Formen bewohnt; so ist die rudimentäre Zivilisation dieses Reiches durch die Unschuld der Sitten seiner Bewohner, durch den guten Geschmack ihrer einfachen Kleidung, durch die grazile Anlage ihrer Feste und Zeremonien und mehr als alles andere durch die großzügige Ausdehnung ihrer Gastfreundschaft wohl dazu angetan, vorteilhaft mit jener anderen Zivilisation verglichen zu werden, welche die von Eisen bedeckten Konquistadoren in den Spitzen ihrer Lanzen, in den Hufen ihrer Pferde und in den Eckzähnen ihrer Jagdhunde mit sich schleppten. ${ }^{4}$

4 Galván, Manuel de Jesús: Enriquillo. Leyenda histórica dominicana (1503-1538). Santo Domingo: Ediciones de Taller 1985, S. 7. 
In diesem ersten Abschnitt des Romans ist, wie sich das für ein gutes Incipit gehört, die Grundstruktur wie der weitere Verlauf des gesamten literarischen Textes angelegt, ja vorgegeben. Zunächst hebt der Erzähler, im Gestus des Historikers und im Antlitz der Universalgeschichte des gesamten Erdkreises, die Bedeutsamkeit des von ihm in der Folge dargestellten Geschehens und seiner Örtlichkeit heraus, vergleicht er doch das indianische Reich von Jaragua mit den Gegenständen von Geschichte und Mythologie der klassischen (und das heißt: der europäischen) Antike. Er stellt seinen Gegenstand ebenso der mythischen Landschaft Arkadiens wie der Welt der Hesperiden, der Inseln der Glückseligen, auf gleicher Augenhöhe an die Seite, womit er von Beginn an derlei verlorene Welten dazu benutzt, die von ihm selbst herausgearbeitete verlorene Welt amerikanischer Unschuld semantisch antikisierend aufzuladen und mit den großen Menschheitsmythen zu verknüpfen. Sprechen wir folglich vom indigenen Reich von Jaragua, so sprechen wir von einem Goldenen Zeitalter, das nicht mehr ist, aber vor weniger als vierhundert Jahren einst auf dieser Insel - folgen wir dem dominikanischen Autor - bestand.

Die mythisch-antikisierende Welt einer unschuldigen und unbefleckten Natur dieses Goldenen Zeitalters erscheint sodann im zweiten Satz vor den Augen der „modernen Argonauten“, mit denen in erster Linie Christoph Kolumbus und seine Männer gemeint sind, die im Übrigen in der Folge eine wesentliche Rolle innerhalb dieses Historischen Romans spielen werden. Diese antiken Helden und modernen Argonauten begründen mit ihrer ersten Entdeckungs- und Eroberungstat einen entscheidenden geschichtlichen Einschnitt, den man als den der Moderne im Sinne von Neuzeit bezeichnen kann. Sie treten dem Reich des Wunderbaren gegenüber, womit ein Grundthema angestimmt wird, das gerade im Bereich der karibischen Literaturen sich von den ersten Briefen des Kolumbus quer durch die Literaturgeschichte bis in unsere Gegenwart verfolgen lässt. Denn es ist - wie wir aus einem früheren Exkurs unserer Vorlesung wissen - nur wenige Jahrzehnte her, dass der kubanische Autor Alejo Carpentier justament von der Insel Hispaniola, freilich ihrer westlichen, haitianischen Hälfte ausgehend, seine literarisch-kulturelle Theorie vom „real maravilloso“ entwickelte und erstmals (mit allen Folgen für die lateinamerikanische Literaturgeschichte) anhand seines Romans El reino de este mundo vorführte.

Bei Manuel de Jesús Galván freilich sind wir im Reich der Indianer von Jaragua; ein Reich, das immer wieder Literaten anlockte, die auf den Spuren der Chronisten der schönen, rätselhaften, unschuldig bedrängten und umgebrachten Königin Anacaona nachspürten. Natürlich ist sie auch ein Gegenstand in Enriquillo; wie hätte sich der Autor dies entgehen lassen können? Wir tauchen ein in das Wunderbar-Wirkliche der karibischen Kultur - so zumindest könnten wir aus der Perspektive Carpentiers diese Einführungssätze von Manuel de Jesús Galván deuten. 
Mit der Ankunft dieser modernen Argonauten beginnt die Geschichte - und zwar in des Wortes dreifacher Bedeutung: Es beginnt erstens die Geschichte des Romans Enriquillo und es beginnt zweitens die Geschichte der Insel und der Region, deren Ursprünge sich mit den wenig später ausgerotteten indigenen Völkern im Dunkel verlieren. Drittens beginnt die Geschichte Amerikas beziehungsweise die Eroberungsgeschichte überhaupt, so wie sie sich noch für die amerikanischen Intellektuellen in der zweiten Hälfte des 19. Jahrhunderts darstellte, die wenig über die altamerikanischen indianischen Kulturen wussten. Genau an diesen Ursprung also legt Galván den Beginn eines Romans, der mit dem Eintritt der Insel La Española oder Hispaniola in die abendländische Expansionsgeschichte einzusetzen scheint.

Und dies war ein Eintritt, der Folgen hatte, wie schon in diesem ersten Absatz klar wird. Denn nun treten sich zwei Zivilisationen einander feindlich gegenüber, die eine rudimentär, aber unschuldig und wunderschön, die andere waffenstarrend, expansionistisch und - wie es scheint - entschlossen, dem Wunderbar-Wirklichen ein sehr reales Ende zu bereiten. Die Kritik an der Conquista, dies haben wir schon bemerkt, war bei den romantischen Autoren recht verbreitet, was sie freilich - wie sich auch anhand dieses Romans zeigen ließe - nicht davon abhielt, die historische Gestalt des Kolumbus romantisch zu überhöhen, zu idealisieren sowie $\mathrm{zu}$ antikisieren. Die modernen Argonauten waren auf der Suche nach dem Goldenen Vlies gekommen und entschlossen, das Gold des goldenen Zeitalters zu rauben.

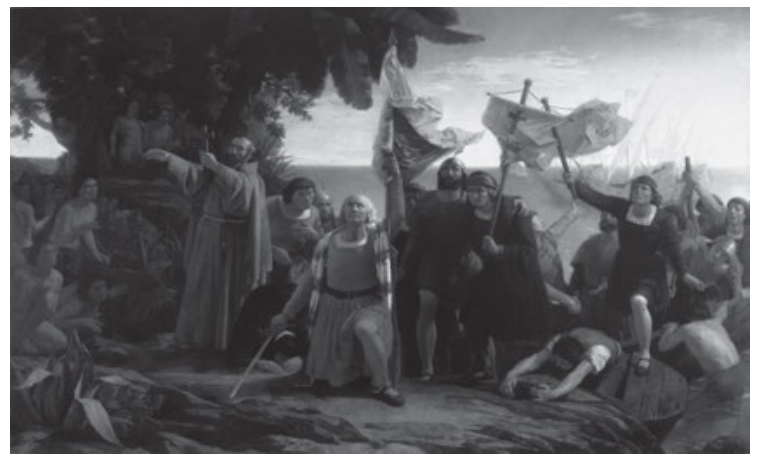

Abb. 59: „Desembarco de Colón“, Öl auf Leinwand von Dióscoro Puebla, 1862.

Die anmutig schönen Eingeborenen, die diese Neue Welt in Galváns Roman bevölkern, scheinen wirklich einer anderen, besseren Welt zu entstammen. Diese „raza benigna“ - und erneut ist der Begriff der „Rasse“ deutlich kulturell und nicht biologisch gemeint - scheint mit ihren einfachen Freuden, ihrem guten Geschmack, den schönen Festen und der Gastfreundschaft direkt aus Jean-Jacques Rousseaus zweitem Discours sur l'origine et l'inégalité parmi les hommes und mehr noch aus 
den Büchern der Rousseauisten entsprungen. Diese hatten ein Jahrhundert zuvor die Berichte in Louis Antoine de Bougainvilles Reise um die Welt - insbesondere über Tahiti, dem neuen Kythera - verzückt und moralisch überwältigt gelesen. Kein Zweifel: Wir befinden uns in Arkadien, so wie einst auch Christoph Kolumbus beim Anblick der Inselwelt sich nahe am Irdischen Paradies gefühlt und geglaubt hatte! Und ähnlich wie diesen erwartet inmitten einer solchen Landschaft die Leserinnen und Leser ein Inferno brutaler Gewalt, wie in jedem besseren Historiengemälde angekündigt durch die aufgerichteten Speerspitzen der Krieger, die über diese Idylle hereinbrechen. Die neuzeitliche Eisenzeit - so könnten wir flott formulieren - bringt Feuer und Schwert nach Arkadien! Der Übergang zur Moderne ist mit dem Tod des Mythischen, des Unschuldigen, des Wunderbaren erkauft: Dies sind Einsichten und Kontraste, wie sie gerade die Romantik auch in Lateinamerika im Verlaufe des 19. Jahrhunderts ein ums andere Mal wiederholte.

In der skizzierten Auseinandersetzung zwischen den Guten und den Bösen stehen die Sieger schon fest: Es sind die für den Kampf Gerüsteten, die in Rüstungen Steckenden, die die Welt der Gastfreundschaft und Güte zerstören, um sich persönlich zu bereichern. Dieser Prozess - unter dem Vorschein der Geschichte wahrhaftig gemacht - wird dem Lesepublikum schon zu Beginn des historischen Romans signalisiert; freilich nur, um danach umso besser in den noch offenen Kampf eintauchen und wenigstens noch ein Stückchen arkadischer Lebenslust genießen zu können. Denn in der Darstellung indigener Lebenskunst, gepaart mit freigebiger Gastfreundschaft tauchen all jene Ideale auf, welche in einer sich modernisierenden Gesellschaft $\mathrm{zu}$ verschwinden drohen. Und eben diesen Grad sozioökonomischer Modernisierung zeigt die Idealisierung der verschwundenen indianischen Welt ebenfalls an.

Der Roman bietet auf diese kontrastreiche Weise dem Lesepublikum eine Idylle an, die allerdings aus der exotisierenden Perspektive der Nachfahren jener Lanzenträger dargestellt wird, welche den Sieg davontrugen und die ideale Welt menschlichen Zusammenlebens auslöschten. Das indianische Reich von Jaragua - und darin liegt die ganze Ambivalenz des Geschehens und mehr noch dieser romanesken Darstellung verborgen - wird auf eine Stufe mit der abendländischen Antike gestellt, zugleich aber mit dieser vermengt, von dieser vereinnahmt, in diese aufgelöst. Ganz im Sinne von Tzvetan Todorov ${ }^{5}$ ist das Andere zum Eigenen geworden und zugleich seiner Differenzqualität verlustig gegangen: Die indianischen Gesellschaften in der Karibik sind das Goldene Zeitalter der Antike.

5 Vgl. Todorov, Tzvetan: La conquête de l'Amérique. La question de l'autre. Paris: Seuil 1982. 
Damit wird zugleich die Grundlage einer Identifikation mit einem derart gereinigten Anderen - als eigentlich Eigenem - und so mit der ureigensten Geschichte geschaffen, wobei sich die weißen Dominikaner nicht als Nachfahren der Spanier, sondern irrtümlich jener idealisierten Gestalten verstehen, welche sie als Indianer verehren. Auf eben diese Weise verstanden sich die amerikanischen Kreolen in ihrem Kampf um die Independencia als legitime Nachfahren der indigenen Bevölkerung, für deren Rechte sie zu kämpfen vorgaben. Als diese Indianer freilich eigene Rechte vorzubringen wagten und aus einer passiven Rolle heraustreten wollten, wurden sie von den kreolischen Trägerschichten der Unabhängigkeitsrevolution erbarmungslos zum Schweigen gebracht. In der Dominikanischen Republik stand solches freilich nicht zu befürchten: Es gab auf Hispaniola, von wenigen versprengten Nachfahren abgesehen, praktisch keine indigene Bevölkerung mehr, die sich noch hätte wehren können.

Das dominikanische Lesepublikum der zweiten Hälfte des 19. Jahrhunderts erhält in Manuel de Jesús Galváns Enriquillo ein Identifikationsangebot, das es dieser Leserschaft nicht nur erlaubt, die Geschichte des Zusammenpralls der Kulturen und des Genozids an den Indianern gleichsam vorgeschichtlich zu entschärfen. Der Roman gestattet es, zugleich die eigene Identität aus dem Anderen, welches gleichsam entkernt letztlich das Eigene in der Verkleidung des Anderen ist, zu beziehen. Es kann dies im Übrigen ungestraft tun, da das Andere als bedrohliche Macht ja gerade durch das böse Eigene - von dem man sich in der gleichen Bewegung wundersam loslöst und dessen man sich entledigt - aus der Welt geschafft wurde. Et in Arcadia ego könnte sich der Dominikaner gegen Ende des 19. Jahrhunderts gesagt haben: Auch ich bin in Arkadien!

Die spanische Conquista, die der „poética existencia“ des Reiches von Jaragua ein plötzliches Ende bescherte, ${ }^{6}$ ist sozusagen das Sprungbrett, mit Hilfe dessen man sich aus der Welt des Eigenen und aus der eigenen Geschichte scheinbar herauskatapultiert - ohne jedoch das eigentlich Andere erreichen zu müssen. Denn der Sprung fällt zu kurz aus und man landet unversehens im Eigenen, der eigenen abendländischen Kultur mit ihren Mythen und Projektionen: „Wir sind alles dominikanische Indianer“ - so lässt sich ein wenig ironisiert das Identifikationsangebot des Romans von seinem stark an historiographische Schreibmuster angelehnten Beginn an umreißen. Und dieses Identifikationsangebot hatte Erfolg, ja großen Erfolg!

Mit Galváns Enriquillo ist der Indianer zum Objekt, nicht aber zum Subjekt der Geschichte geworden. Und diese Geschichte ist indianistisch, keinesfalls indigenistisch und schon gar nicht eine Geschichte aus Perspektive der indigenen Bevöl-

6 Galván, Manuel de Jesús: Enriquillo, S. 8. 
kerung und ihrer Kultur. Nicht von ungefähr muss der Erzählerdiskurs vermittels einer Fußnote ${ }^{7}$ betonen, dass es nicht um übertriebene Indianerfreundlichkeit, sondern um Mitleid („,compasión“) mit den von den Spaniern besiegten und ausgerotteten Indianern gehe. Alterität wird in Exotik zurückgenommen, wird also zum Anderen in für das Eigene leicht konsumierbarer Form und sogar zum Teil der eigenen Kulturgeschichte. Dass dies für die Dominikanische Republik ein nationales Identifikationsangebot war, welches sich zugleich entschieden vom ,schwarzen“ Haiti abwendet, mit dem man sich die Insel Hispaniola teilen muss, sei an dieser Stelle nur erwähnt. Doch lässt all dies erahnen, warum der Roman Enriquillo von solcher Wichtigkeit für den kulturellen Nationenbildungsprozess der Dominikanischen Republik werden konnte.

Vom historisch bezeugten Untergang des paradiesischen Reiches der wunderschönen Königin Anacaona nimmt das Romangeschehen seinen Ausgang: zu einer Zeit, als Santo Domingo - so belehrt uns der historiographische Erzählerdiskurs - zum Ausgangspunkt der Zivilisation in der Neuen Welt wurde. Den Übergang vom historiographisch-narrativen zum fiktional-narrativen Erzählerdiskurs (wobei sich die historiographische Instanz vor allem dann um so stärker in den paratextuellen Fußnoten bemerkbar macht) bewerkstelligt der Hinweis, dass nun zwanzig Tage vorüber seien und der Gobernador der Insel Española und Statthalter des spanischen Königs, Nicolás de Ovando, brutal gehandelt habe. Denn er habe achtzig Kaziken und damit die Führungselite der Insel ermorden lassen. Doch nicht nur Massaker an der indigenen Bevölkerung bestimmen die Strategie der Spanier. Denn die Tochter der schönen Anacaona, die ebenfalls schöne Higuemota, wurde durch Heirat mit dem guten Christen Guevara zu Doña Ana de Guevara. ${ }^{8}$ Die indigene Bevölkerung wird nach bewährtem Muster an ihrer Spitze entweder umgebracht oder genetisch einverleibt.

Der Paratext in Form einer Fußnote belehrt das Lesepublikum literaturgeschichtlich, dass sich bereits der auf historische Stoffe spezialisierte US-amerikanische Autor Washington Irving, ein wichtiger Bezugsschriftsteller Galváns, mit dem Leben der schönen Prinzessin beschäftigt habe. Mencía, Tochter dieser indianischen Prinzessin und eines Spaniers adliger Abkunft, wird als künftige scheue Liebespartnerin eine gewisse (wenn auch eher passive) Rolle innerhalb des Romangeschehens spielen. Hauptfigur ist der zu Beginn des Romans siebenjährige Guarocuya, der - ebenso wie Higuemota - als ,Edler Wilder‘ völlig unfähig zur Lüge ist. ${ }^{9}$ Beide Figuren verfügen ebenso über einen indigenen wie einen spa-

7 Ebda., S. 51.

8 Ebda., S. 9.

9 Ebda., S. 135. 
nisch-christlichen Namen, so dass der junge Mann später zum Titelhelden des Romans werden kann, zu jenem Enriquillo, der ins Zentrum der gesamten Romanhandlung und zugleich aller Identifikationsangebote gerückt wird.

Als Sohn eines ebenfalls von den Spaniern getöteten Kaziken ist Enriquillo von indianischer Abstammung edelsten Geblüts. Daher erstaunt die große Aufregung bei den Spaniern nicht, als sie erfahren, dass der Junge von einem Überlebenden dieses Massakers, dem indianischen Prachtkerl Guaroa, ins indigene Hinterland verbracht wurde. Guaroa verwickelt sich freilich in Widersprüche, welche - so klärt uns der Erzähler in einer Fußnote auf - charakteristisch seien für Menschen „a medio civilizar“, ${ }^{10}$ die also nur halbzivilisiert seien. Enriquillo wird folglich aus der Obhut Higuemotas in die von Indianern besiedelten Rückzugsgebiete der Bergregionen geführt, nicht ohne dass der junge Kazike der kleinen Mencía artig einen Kuss auf die Lippen gedrückt hätte. Im indigenen Bergland stellt dieser jugendliche Anführer freilich eine latente Bedrohung für die spanische Herrschaft über die Insel dar.

Übrigens tauchen im Diskurs von Guaroa erstmals positive Spanier-Gestalten auf, und zwar niemand Geringeres als die beiden Brüder des Christoph Kolumbus sowie der gute Bartolomé de las Casas, der bald schon zum großen Beschützer der indigenen Bevölkerung avanciert. Sie stehen in Kontrast zu den meisten anderen Spaniern, die als hochfahrend, gerissen, gewalttätig und machtbewusst dargestellt werden; allen voran die Gestalt des verschlagenen und grundlegend bösen Pedro de Mojica, der die Familie Higuemotas und deren Vermögen beaufsichtigen darf und dem in diesem Roman die Rolle des Schurken zufällt. Die Figurenkonstellation - dies wird von Beginn an deutlich - ist stark antithetisch und manichäisch ausgerichtet: Schnell erkennen die Leserinnen und Leser die Guten wie die Bösen und wissen sie voneinander zu scheiden. Freilich gibt es auch historische Figuren wie Diego Velázquez, die laut Erzählerdiskurs ständig zwischen beiden Polen schwanken ${ }^{11}$ und der Hilfe guter Menschen bedürfen, um auf den Weg des Heils zurückzukehren. Mojica jedenfalls hat es auf das nicht unbeträchtliche Vermögen Higuemotas und - als Pars pro toto metonymisch verschoben - insgesamt auf den Reichtum der Indianer abgesehen, die er zu betrügen und um ihre angestammten Rechte zu bringen versucht. Kompromisslos wird er alles daran setzen, seine Ziele zu verwirklichen und zu einem reichen Mann zu werden.

Guarocuya oder Enriquillo, wie wir ihn fortan nennen wollen, ist - wie die Indianer in den Bergen unterstreichen - natürlicher Erbe der Herrschaft ${ }^{12}$ und

10 Ebda., S. 16.

11 Ebda., S. 163.

12 Ebda., S. 25. 
damit potentiell für die Spanier höchst gefährlich. Der kleine Kazike wird sogleich in seine angestammten Rechte eingesetzt, wenn Guaroa auch noch übergangsweise die Indianer befehligen soll. Er baut als erstes gegen die Spanier ein wahres Frühwarnsystem, wobei als letzter Zufluchtsort ein Süßwassersee im Nordosten der Gebirge im Landesinneren vereinbart wird; ${ }^{13}$ eben jener See, der später den Namen Enriquillos tragen sollte und bis heute trägt. Damit ist er zu Beginn des Romans schon als kleiner Junge in jener Position, die er gegen Ende seines Lebens dann in seiner vollen Größe ausfüllen wird: Er wird zum heroischen Widerstandskämpfer für seine ,verlorene Rasse‘ in den Bergen Hispaniolas. Wir erleben die Schaffung einer Insel-Welt, einer isolierten Welt, die versucht, sich von den Zeitläuften jenseits der Ozeane abzukoppeln.

Die hochgerüsteten und $\mathrm{zu}$ allem entschlossenen Spanier geben selbstverständlich nicht klein bei. Eine erste Strafexpedition unter Diego de Velázquez scheitert jedoch, da es ihr nicht gelingt, den Befehl Ovandos umzusetzen, die aufständischen Indianer wie Rebellen zu behandeln, also kurzen Prozess mit ihnen $\mathrm{zu}$ machen und dem Joch der Zivilisation ${ }^{14} \mathrm{zu}$ unterwerfen. Der fatale Einfluss dieser Art von ,Zivilisation“ ist deutlich, zeigt der Erzählerdiskurs doch auf, dass die Indianer unter der spanischen Tyrannei rasch ,degenerierten' ${ }^{15}$ Doch Guaroa ist zunächst fähig, aufgrund einer klugen Guerilla-Taktik, die auch Enriquillo später anwenden wird, sich die Spanier vom Leibe zu halten und sogar einige von ihnen zu töten.

Alles wirkt wie ein Präludium kommender Heldentaten des jungen Kaziken. Der Weg zurück an die Macht, der über die spanische Erziehung des intelligenten Indianers verläuft, wirkt hingegen wie ein Umweg oder Irrweg, der ihn weiter von seinem Ziel entfernt. Und doch macht dieser Umweg die eigentliche Größe Enriquillos aus, vereint er so in seiner Gestalt doch die positiven Eigenschaften der Indianer wie der Spanier und wird auf diese Weise zur identifikationsfähigen Fusionsfigur des Besten beider Welten. Die indigenen Kulturen treten in diesem Schema folglich wieder in ihr Recht und präsentieren sich - zumindest auf historischer Ebene - als ein kultureller Pol, der in den Amerikas grundsätzlich zu berücksichtigen wäre.

Der historische Roman Manuel de Jesús Galváns wird auf dieser Ebene somit zum Bildungsroman, der dialektisch beide Kulturen miteinander vermittelt und geradewegs den Kaziken dazu führt, die Spanier auf Grund der von diesen propagierten positiven Werte zu bekämpfen. Novela sentimental und mehr noch his-

13 Ebda., S. 26.

14 Ebda., S. 34.

15 Ebda. 
torischer Roman, Bildungsroman und indianistisches Zeitdokument: Enriquillo vereint eine Vielzahl literarischer und ideologischer Positionen in einer Funktionszuweisung der Literatur, die deutlich pragmatischen Zuschnitts ist. Im idealisierenden historischen Rückblick auf die erste Phase der ,Entdeckung ' und Eroberung werden die indigenen Kulturen zu einer kulturellen Alternative im Entwicklungsgang der verschiedenen Areas des künftigen Amerika - so zumindest ließe sich die indianistische Position von Manuel de Jesús Galván deuten.

Der Auftritt des „Licenciado“ Bartolomé de las Casas ist recht spektakulär in Szene gesetzt, ist er es doch, dem es als Indianerfreund gelingt, die Indios davon zu überzeugen, den kleinen Enriquillo (der mit offenen Armen auf den künftigen Priester und Mönch zuläuft) wieder aus den Bergen in die Stadt zurückkehren zu lassen. Damit integriert er sie in den Einflussbereich der spanisch-europäischen Kultur. Die politischen Vertreter dieser christlichen Zivilisation aber setzen gegenüber den Indianern nicht auf Menschlichkeit, sondern auf rohe Gewalt, auf Unterwerfung und Ausrottung: Ovando kennt kein Pardon mit denen, die für ihn nichts als „Rebellen“ sind.

Einzige Zufluchtsorte der Menschlichkeit sind neu gegründete Klöster, etwa das Franziskanerkloster, in welchem Las Casas den Jungen unterbringt und ihn auf den Namen Enrique taufen lässt. ${ }^{16}$ Da es sich bei ihm um einen kleinen Kaziken handelt, um einen „caciquillo“, wird aus Enrique rasch ein Enriquillo. Währenddessen werden die armen, wehrlosen Indianer von der spanischen Soldateska auf Ovandos Befehl hingemordet und der „obra de exterminio“, also der Ausrottung zugeführt. ${ }^{17}$ Heldenhaft findet dabei auch Guaroa den Tod in Freiheit: den Freitod, den wir bei den entflohenen schwarzen Sklaven in der Karibik bereits kennengelernt hatten. Hohe Selbstmordraten sind bis heute auf den Antillen nichts Außergewöhnliches.

Längst ist auch die schöne Anacaona ermordet worden und die Elite der Indianer mit Ausnahme Enriquillos ist aus dem Weg geräumt. Die Einbettung dieser und anderer historischer Geschehnisse - etwa auch von Anmerkungen zur Entdeckungsreise des Kolumbus an die Küste Jamaicas - wird in den Fußnoten oft mit dem lapidaren Hinweis versehen, es handle sich um historische Tatsachen. Eine Vorgehensweise, die wir bereits aus Cecilia Valdés kennen: Historisch ist, was glaubhafte Bezugstexte aufweisen kann.

Eine dieser ,Quellen', dieser literarischen Intertexte sind die Schriften des im Roman immer wieder vorteilhaft in Szene gesetzten Las Casas, der angesichts der blutigen und grausamen Niederschlagung berechtigter Indianeraufstände

16 Ebda., S. 56.

17 Ebda. 
Ovando ins Gesicht sagt, er werde dies eines Tages niederschreiben und für die Nachwelt gegenwärtig halten. ${ }^{18}$ Selbst Christoph Kolumbus, nach langen Irrfahrten und gefahrvollen Abenteuern seit 1504 wieder in Santo Domingo, kann nur mehr entgeistert den Kopf schütteln angesichts des Zustandes der laut Erzählerdiskurs so sehr von ihm geliebten indianischen ,Rasse‘, die der Ausrottung nahe sei. Seine Tränen gelten auch dem Tod der schönen Anacaona. Der ebenso schönen Mencía prophezeit der Admiral, dass sie sehr hübsch und daher auch sehr unglücklich sein werde. Doch Kolumbus' Stern selbst, dies macht der Erzählerdiskurs ein ums andere Mal deutlich, ist längst im Sinken begriffen: Im Mai 1506 wird der sogenannte ,Entdecker‘ der sogenannten ,Neuen Welt‘ im spanischen Valladolid sterben ${ }^{19}$ - noch immer davon überzeugt, einen Seeweg nach Indien und China gefunden zu haben.

Derweil beginnt die jahrelange, hervorragend orchestrierte Ausbildung und Erziehung Enriquillos im Franziskanerkloster, das - so klärt uns der Erzähler auf - zum Zeitpunkt der Niederschrift des Romans längst nicht mehr bestehe. Die tiefe Melancholie kann Enriquillo jedoch nicht genommen werden, ist sein großes Problem doch die „orfandad“, sein Zustand als Waisenkind. Es sind dies die Bildungsjahre eines jungen Romantikers, der noch immer am „mal du siècle“ partizipiert und seine Melancholie niemals abzulegen vermag. Größte Begeisterung erwecken in ihm jedoch die Erzählungen römischer Geschichtsschreiber, ${ }^{20}$ besonders dann, wenn sie von Aufständen gegen die Römer berichten. Spartakus, den schon die schwarzen Sklaven von Saint-Domingue zum Vorbild nahmen, ist nicht fern. Und so wird zugleich ein bereits von den europäischen Aufklärern und Kolonialschriftstellern wie Diderot und Raynal gepflegtes Motiv eingeführt, das nicht nur Jaragua, sondern auch Enriquillo selbst in die Traditionslinie abendländischer Modelle stellt. Der schwarze Spartakus Raynals, die Rächer-Figur, die stets schon über Sabs Schicksal schwebte - wird sie nun fiktionale Wirklichkeit mit Enriquillo? Nein! Enriquillo wäre auf der dominikanischen Seite der Insel Hispaniola nicht zur nationalen Identifikationsfigur geworden, wäre er selbst zum indianischen Spartakus herangereift: Mit einem solchen hätte sich kaum einer identifiziert.

In der Zwischenzeit hat Don Diego Colón, der Bruder des Christoph Kolumbus, auf Anweisung der auf dem Totenbett liegenden Königin Isabela die Amtsgeschäfte Ovandos auf der Isla Española übernommen. Grund genug für den Autor, an diesen Stellen etwas langatmige Einblendungen zur Geschichte von Christoph

18 Ebda., S. 68.

19 Ebda., S. 75.

20 Ebda., S. 78. 
Kolumbus' Bruder und dessen Benachteiligung durch den spanischen Hof einzuflechten. Auch bei der Darstellung der Liebesgeschichte Don Diego Colóns vergisst der Erzähler niemals, von unserem wahrheitsgemäßen Bericht zu sprechen, „nuestro verídico relato“, ${ }^{21}$ und die historische Authentizität des Berichteten zu unterstreichen. Im Sommer des Jahres 1509 trifft das verliebte Pärchen in Santo Domingo ein. Doch die Macht von Colóns Bruder über die Insel wird von Beginn an untergraben, ungeachtet der begeisterten Aufnahme, die er zunächst erfährt. ${ }^{22}$ Für diese Passagen ruft Manuel de Jesús Galván stets den Chronisten Antonio de Herrera und dessen Décadas, also die Historia general de los hechos de los castellanos en las Islas y Tierra Firme del mar Océano que llaman Indias Occidentales, in den Zeugenstand, bisweilen gar in Form von Zitaten, welche in die Fußnoten und Anmerkungen mitaufgenommen werden. Man versteht nun besser, warum José Martí von einer anderen Art sprechen konnte, Amerikas Geschichte zu erzählen.

Eine Reihe zwischengeschalteter Historias und Berichte, insbesondere zu historischen Gestalten wie Juan de Grijalva oder Hernán Cortés, dürfen wir an dieser Stelle getrost überspringen. Weit aufschlussreicher als diese intertextuellen Beziehungen zu historiographischen Texten scheinen mir Überlegungen, die der Erzähler zu Beginn des zweiten Teils bezüglich der von ihm dargestellten Epoche anstellt: Durchaus nicht im Sinne der europäischen Romantiker erscheint das Mittelalter ganz als Epoche der Finsternis und des Präludiums für die nachfolgende rationale Klarheit; eine Vision, die sehr wohl im Gegensatz zur europäischen Mittelaltersicht der Romantik das Dunkle dieser Zeit gerade nicht im Sinne einer Epoche des Glaubens und der Mystik gegen den kühlen Rationalismus der Aufklärung ins Feld führt.

Es scheint mir folglich charakteristisch für die Romantik in Lateinamerika insgesamt zu sein, dass sie sich nicht oder nur sehr beschränkt als Gegenschlag gegen den Rationalismus, gegen das Zergliedern des analytischen Geistes der Aufklärung verstehen lässt, sondern sich eher in eine historische Kontinuität mit ihr stellt, die in den amerikanischen Kolonien ebenfalls sehr stark war. Wir werden uns der Aufklärung zwischen zwei Welten in einer eigenen Vorlesung noch gesondert widmen, ist doch gerade im Bereich der Aufklärungsforschung in den bisherigen Analysen in Europa sträflich vernachlässigt worden, auch die Aufklärung als eine Epoche zwischen zwei Welten zu begreifen. Für das Gros amerikanischer Schriftsteller der Romantik war diese Erkenntnis selbstverständlich. Wir stoßen just an dieser Stelle auf eine historische und kulturelle Besonderheit insbesondere in den ehemals iberischen Kolonien der Neuen Welt, nämlich in Europa als

21 Ebda., S. 95, 99 und passim.

22 Ebda., S. 102. 
Gegensätze verstandene Bewegungen lediglich als Differenzen zu interpretieren, welche sehr wohl in eine geschichtliche Kontinuität integriert werden können.

Eine derartige Positionierung selbst von europäischen Großepochen ist angesichts der anderen gesellschaftlichen Situation und sozialen Funktion von Literatur in den jungen Staaten des amerikanischen Kontinents mehr als verständlich. Denn es gab keinen Grund, nach einer erfolgreichen Independencia, welche auch das Ergebnis aufklärerischen Wirkens einheimischer Philosophen war, an den positiven Ergebnissen einer Epoche zu zweifeln, welche Freiheit und Unabhängigkeit im nationalen Maßstab heraufgeführt hatten.

Wie sich dies mit der literarischen Darstellung romantischer Liebesgeschichten verträgt, werden wir gleich sehen. Nehmen wir als Beispiel die historische Gestalt des Vaters der schönen María de Cuéllar, die eine beiderseitig unglückliche Liebe zum nicht weniger historischen Juan de Grijalva verbindet. María wurde von ihrem Vater einem anderen versprochen, was so etwas wie ihr Todesurteil darstellt. Doch sehen wir selbst:

\footnotetext{
Es gehörte der Königliche Zahlmeister Don Cristóbal de Cuéllar durch seine Prinzipien und seine Vorstellungen zu jenem Jahrhundert, in dem er geboren ward; diesem fruchtbaren fünfzehnten Jahrhundert, welches das dunkle Mittelalter mit dem Fall des Oströmischen Reiches, der Eroberung von Granada sowie der Entdeckung der Neuen Welt abschloss. Zur Hälfte Schatten und zur Hälfte Licht, bildete jenes Jahrhundert in seinem Verklingen das würdige Vorspiel zum großen Jahrhundert der Renaissance, der Wiedergeburt der Literatur und der Künste, zu dem die Emigration der berühmtesten Gelehrten und Literaten aus dem bereits mohammedanischen Konstantinopel nach Italien so viel beitrug. [...]

Im Bewusstsein der Völker setzte sich damals die Vorstellung von der königlichen Macht durch, so wie sich heute die demokratische Idee unter der rationalen Form der Republik behauptet, die eine Folge des größten Fortschritts der moralischen und politischen Wissenschaften darstellt. ${ }^{23}$
}

So wird eine tragische Liebesgeschichte in Überlegungen zur Epochenwende zwischen Mittelalter und Renaissance integriert. Wenn nicht alles, so erhält doch vieles eine umfassende literarisch-philosophische Kontextualisierung. Diese geschichtsphilosophischen Reflexionen der Erzählerfigur gehen in der angeführten Passage von einem altbekannten Epochenmodell aus, das zugleich zeitbezogen ist auf die Erzählzeit des ausgehenden 19. Jahrhunderts und eine demokratisch-republikanische Staatsform auch für die entstehende Dominikanische Republik anstrebt.

Gleich im Anschluss an zitierte Passage weist der Erzähler aber ebenfalls darauf hin, dass es bisweilen (und bis zum heutigen Tage) sehr wohl vorkomme,

23 Ebda., S. $123 \mathrm{f}$. 
dass durch die zu starke Verherrlichung von Autorität die Geschichte des Fortschritts angehalten werde, es sogar zu Rückschritten kommen könne. Dies habe zur Folge dass der Triumphwagen der Zivilisation und des Rechts mitunter seinen Weg nicht weiterverfolgen könne. ${ }^{24}$

Diese Überlegungen machen deutlich, dass zum einen der Erzähler sehr wohl universalistisch beziehungsweise globalgeschichtlich denkt, die Geschichte seines Landes, seiner Insel also integriert in die großen weltgeschichtlichen Entwicklungen. Zugleich aber ist dieser universalistische Ansatz verbunden mit einer universalisierenden Sichtweise, in welcher die allgemeine Entwicklung hin zu demokratischen Prinzipien einen Prozess darstellt, der alle Gesellschaften des 19. Jahrhunderts weltweit erfasst habe. Der arealen und regionalen Besonderheit der Karibik wird in diesen Überlegungen des Erzählers nur ein geringer Platz eingeräumt. Warum ist dies der Fall? Die Karibik als Drehscheibe der Weltgeschichte ist - dies wird unter anderem an zitierter Stelle deutlich - in ihrer Geschichte stets ihrem Selbstverständnis nach Weltgeschichte. Ihre eigene Geschichte produziert sie als extrem außenabhängige Region nur im Sog der Weltgeschichte - und diese ist bis zum Zeitpunkt des Erscheinens des Romans und damit noch vor Beginn der dritten Phase beschleunigter Globalisierung im Wesentlichen europäisch geprägt. Nicht umsonst zählt der karibische Raum als Area zu den am frühesten globalisierten Bereichen unseres Planeten und spielte nach der ersten auch in der zweiten Phase beschleunigter Globalisierung eine entscheidende globalgeschichtliche Rolle. Wir werden noch mehrfach auf dieses für die Area charakteristische Selbstverständnis der Karibik stoßen.

Bemerkenswert ist des Weiteren die Beobachtung, dass die Erzählerfigur von Manuel de Jesús Galván die Demokratie als angestrebte Regierungsform bezeichnet; zu einem Zeitpunkt, als es in Hispanoamerika eine Reihe von Diktaturen gibt, deren damals bekanntester, jener des mexikanischen Generalissimus Porfirio Díaz, noch ein langes Leben bis zur Mexikanischen Revolution beschert sein sollte. Galváns Erzähler ließe sich hier auf jene oberflächlichen Demokratisierungstendenzen beziehen, die Ángel Rama im Umfeld des Modernismo seit dem letzten Drittel des 19. Jahrhunderts erkannt zu haben glaubte. ${ }^{25}$ Auch in dieser Hinsicht - so ließe sich hinzufügen - wäre Galváns Buch mit seiner noch von der Romantik getragenen Intentionalität ästhetisch bereits verspätet.

Kehren wir auf die Ebene der erzählten Zeit zurück! Hier wird die spätere Geschichte der Eroberung und Kolonisation noch als vergangene offene Zukunft

24 Vgl. ebda., S. 124.

25 Vgl. Rama, Ángel: Las máscaras democráticas del Modernismo. Montevideo: Fundación Ángel Rama 1985. 
dargestellt. Es handelt sich dabei um eine Geschichte, die auch anders hätte kommen können, hätten sich die Protagonisten der Conquista (wie etwa die historischen Figuren Ovando, Cortés oder Velázquez) an die weisen Ratschläge des auch heute noch in der spanischen Geschichtsschreibung nicht selten übel beleumundeten Bartolomé de Las Casas gehalten. ${ }^{26}$ Dennoch erscheint die Conquista in den Augen der Galván'schen Erzählerfigur als ein großes Epos, „una gran epopeya“, von großen Männern getragen. ${ }^{27}$ Eine Fußnote klärt den Leser darüber auf, dass sich nicht nur Washington Irving, sondern auch eine ganze Reihe puerto-ricanischer Autoren in neuester Zeit (also in der zweiten Hälfte des 19. Jahrhunderts) mit dieser geschichtlichen Epoche literarisch auseinandergesetzt hätte. Dies ist der Stolz des Dominikaners, dass aus seiner eigenen Area, der Antilleninsel Puerto Rico - die damals noch unter spanischer Herrschaft stand - und nicht nur aus den USA eigene Ansätze für ein Verständnis der eigenen Geschichte erwachsen waren.

Kein Zweifel: Gerade angesichts massiver Entwicklungsschwierigkeiten der einzelnen lateinamerikanischen Nationen einschließlich der spanischen Restkolonien Kuba und Puerto Rico geht der Blick zurück zum Gründungserlebnis dieser verschiedenen Areas, der Conquista, um dort die Gründe für die aktuellen Schwierigkeiten auszumachen. In diesem großen Epos fallen aus karibischer Sicht den Spaniern selbstredend die schlechten Rollen zu. Der spanische Eroberer-Geist, die Herrschsucht, der „Caudillismo“ und das undemokratisch-machtsüchtige Herrschaftselement werden zu Merkmalen, welche die Geschichte der hispanoamerikanischen Nationen negativ beeinflusst hätten. Die Abgrenzung von Spanien, ein Erbe der Bewegung der Independencia, dauert an; und mit ihr die Suche nach einem eigenen Weg soziopolitischer und -kultureller Modernisierung.

Neben Antonio de Herrera, aus dessen Décadas immer wieder auch Passagen in den Anhang des Romans aufgenommen werden, tritt die Figur des Bartolomé de las Casas auf den verschiedensten Ebenen des Textes immer stärker in den Vordergrund. Zum einen bildet er einen wichtigen intertextuellen Bezugspunkt, da insbesondere auf Passagen seiner Historia de las Indias verwiesen und bisweilen daraus zitiert oder paraphrasiert wird. Zum anderen ist er explizit Gegenstand anderer vorwiegend historiographischer Texte wie der Décadas von Herrera und wird sozusagen aus dem Blickwinkel weiterer Autoren gedeutet und beleuchtet. Drittens aber ist er vor allem auch die intradiegetisch dominante Gestalt, die für den Verlauf des Romans eine zunehmend wichtige Funktion, ja eine Schlüssel-

26 Vgl. Galván, Manuel de Jesús: Enriquillo, u.a. S. 181.

27 Ebda., S. 189. 
rolle übernimmt. In struktureller Hinsicht jedenfalls ist die Figur des Las Casas für den Romantext durch ihre dreifache Funktion von fundamentaler Bedeutung und tritt durch die verschiedenartigsten Beleuchtungen der Leserschaft ebenso plastisch wie lebendig vor Augen.

Wir wollen an dieser Stelle versuchen, das literarische Zusammenspiel zwischen den verschiedenen Textebenen etwas genauer zu untersuchen! Die historisch bezeugte und von Antonio de Herrera beschriebene Priesterweihe des Las Casas im Jahr 1510 im Binnenbereich der Isla Española, in der wunderschönen tropischen Landschaft der Vega, gibt ausgehend von der Reise Diego Colóns und seiner Frau María de Toledo, den Vizekönigen, Anlass zu Naturbeschreibungen, die unverkennbar romantische Züge tragen. Sie integrieren in die historische Landschaft Wahrnehmungsweisen einer Korrespondenz-Natur des 19. Jahrhunderts. Darüber hinaus werden aber auch Volksszenen auf dem Lande evoziert, welche durch ihre Idealisierung des Landlebens den würdigen Rahmen für die idyllisch eingebettete, nachfolgende Darstellung der Priesterweihe bieten und an die fast zeitgenössische Schäferlyrik gemahnen:

Nach drei Tagen gelangten sie in die Stadt Concepción de la Vega. Es war jene Epoche des Jahres, in welcher von allen Orten der Insel, wo man Bergbau betrieb, die Kolonisten zu diesem Bevölkerungsmittelpunkt strömten, um ihre Mineralien einzuschmelzen und wie vom Gesetz vorgeschrieben zu markieren; aus diesem Grunde bot die Vega eine so große Belebtheit dar, die wohl noch größer als jene der Hauptstadt war: Zur gleichen Zeit feierte man die Kirchweih, zu der von den abgelegensten Orten des gesamten Territoriums all jene herbeieilten, welche irgend einen Gegenstand, Tiere oder Tand besaßen, die sich gut versteigern ließen. Auf den Hauptstraßen waren die Leute in festlichem Aufruhr [...]. ${ }^{28}$

In diesen Beschreibungen ist Bartolomé de Las Casas noch nicht zu sehen. Und doch ist er bereits präsent, drückt seine tatkräftige und stets offene Menschlichkeit doch ebenso der Landschaft wie den Menschen seinen Stempel auf. Die kolonialen Geschäfte, die Ausbeutung der Minen, die an anderer Stelle angeprangert werden, erscheinen hier in einem so harmonischen, festlichen und friedlichen Licht, das die Idylle des Landesinneren beeindruckend hervortreten lässt und $\mathrm{zu}$ keinem Zeitpunkt in Frage stellt: Es ist, als wohnten wir einer Szene auf dem Lande in Europa bei.

Dann folgt im siebenundzwanzigsten Kapitel des zweiten Teils ein ausführliches Zitat aus der Historia de las Indias, so dass Las Casas nicht nur intradiegetisch als fiktionale Gestalt die Landschaft prägt, sondern zugleich auch noch als Autor, als Schriftsteller darin zu Wort kommt. Damit wird gleichsam der deskrip-

28 Ebda., S. $204 \mathrm{f}$. 
tive Teil aus der Ebene der Romandiegese allograph, von einem anderen Texte her bezogen und einer Romanfigur überantwortet, deren Text authentisch und für die Leser überprüfbar vorliegt.

Dieses literarische Verfahren ist ästhetisch fraglos sehr wirksam. Die kontextuelle Einbettung des Intertexts wirkt so stark, dass man fast geneigt wäre, Las Casas mit der Brille der Romantik zu lesen. Geben wir zumindest einen kleinen Ausschnitt aus dem im fortlaufenden Text angeführten Zitat wieder, um die intertextuelle Arbeit von Manuel de Jesús Galván noch deutlicher hervortreten zu lassen! Die Beschreibung der Vega und deren Wirkung auf die Betrachter lesen sich wie folgt:

Gewisslich gibt es keinen schöneren und anmutigeren Anblick, der mit soviel Lust und Freude alles Innerste umgibt und einhüllt, und auf dem ganzen Erdenrunde kann dies weder hübscher gehört noch vorgestellt werden, da diese ganze fruchtbare Ebene, die so weit und breit ist, noch ebener ist als selbst die Fläche meiner Hand; sie ist gänzlich vom Grase bemalt, das schönste, das man sagen kann, und das duftendste, gänzlich verschieden von jenem in Spanien; wie gemalt sind von Meile zu Meile oder von zwei Meilen zu wiederum zwei Meilen die anmutigsten Bächlein, die sie durchziehen, und jedes einzelne trägt zu beiden Seiten an beiden Ufern eine Liste oder Braue oder Girlande von Bäumen, die stets grün sind und so hübsch angelegt und bestellt, als wären sie von Händen angeordnet und gepflegt, und sie nehmen nicht mehr als 15 oder 20 Schritt' auf jeder Seite ein. [...]

Für gesichert halt' ich's, dass kein Mensch und kein Gelehrter, der dies gesehen und die Schönheit aller Ding' erkannt und die Freude, Heiterkeit und Lage dieser Vega bemerkt, nicht glaubte, vergebens die Reise von Kastilien hierher gemacht zu haben, wär' er neugieriger Philosoph oder gottgläubiger Christ, allein nur um dies zu sehen [...]. ${ }^{29}$

Bartolomé de Las Casas ist selbstverständlich kein Romantiker, sondern kombiniert in klassischer antiker Tradition die einzelnen Elemente des Locus amoenus, um sie dann freilich in christlicher Hinsicht durchzusehen und zum höheren Lobe Gottes zu deuten. Das von ihm beschriebene Bild der Natur ist zweifellos ein literarisch-philosophischer Gemeinplatz, den er mit den höchsten Auszeichnungen versieht, die ihm zu diesem Zeitpunkt möglich waren. Dabei fällt der obligate transatlantische Vergleich, der sich bereits im Bordbuch des Christoph Kolumbus findet, stets zu Gunsten der Neuen Welt aus, deren tropische Vegetation alles übertreffe, was aus Spanien bekannt sei. Die Isla Española erscheint als eine Welt in sich: Ihr Territorium erstreckt sich über eine große Fläche, welche die verschiedensten Nutzungsmöglichkeiten einschließt.

Für die soeben von uns angeführte Passage ist die intertextuelle Ebene überaus interessant, gelingt es Manuel de Jesús Galván doch, Las Casas als his-

29 Galván, Manuel de Jesús [Las Casas]: Enriquillo, S. 212 f. 
torische, als literarische und als fiktionale Gestalt miteinander zu verschmelzen, indem gerade der Schriftsteller Las Casas zum Kreuzungspunkt und Gewährsmann, mithin zum Auctor dieser verschiedenen Ebenen wird. Manuel de Jesús Galván beschränkt sich nicht darauf, sondern fügt in einer Fußnote paratextuell als ob es des Guten noch nicht genug wäre - einen weiteren Text des Dominikanermönches hinzu, um ihn in der Folge im Rahmen des Erzählerdiskurses der Fußnote zu kommentieren. Somit entsteht ein enges Verwoben-Sein des dominikanischen Romans mit den Schriften von Las Casas.

Die intertextuelle Dimension der historischen Romanfigur wird auf diese Weise metatextuell an den eigenen Text herangeführt und in den romantisierenden, teilweise auch (auto-)exotisierenden Kontext von Enriquillo eingebaut; ein Kunstgriff, der sich in der Reihe historischer Romane in Hispanoamerika nur selten findet und in seiner wirkungsvollen Art und Weise besticht. Man könnte formulieren, dass der dominikanische Roman sich den Dominikanermönch gleich mehrfach, auf unterschiedlichen Textebenen einverleibt. Dies belegt einmal mehr, dass die hispanoamerikanischen Romane des 19. Jahrhunderts in Hinblick auf ihre literarischen Verfahren in der Forschungsliteratur oftmals unterschätzt werden und nicht gesehen wird, dass sich ihre textuelle Effizienz keineswegs ,natürlich“ ergibt, sondern auf einem Netzwerk komplexer Textbezüge und Verfahren beruht. In der kulturellen Area der Karibik - und insbesondere der InselKaribik - reicht die historische Erinnerung dabei zurück bis in die Epoche von „Descubrimiento“ und Conquista, von ,Entdeckung“ und ,epischer“ Eroberung. Sie knüpft intertextuelle Bande zu den auf diese Area bezogenen Texten unabhängig davon, ob es sich um historische Entdeckerfiguren, um die Protagonisten der ersten Phase beschleunigter Globalisierung oder um Geschichtsschreiber jener Epoche handelt.

Dieses Verfahren erhält noch dadurch eine zusätzliche Bedeutung, dass wenig später Bartolomé de Las Casas zu den Indianern spricht, sie erstmals als Brüder, als „hermanos en Jesucristo“ bezeichnet und der Erzählerdiskurs keinen Zweifel daran lässt, dass durch Las Casas Gott höchstselbst ${ }^{30}$ zur indigenen Bevölkerung spreche. Dadurch werden auch die späteren Einblendungen von Textstellen des spanischen Dominikaners in diesen heilsgeschichtlichen Zusammenhang gestellt. Ebenfalls verwundert nicht, dass nachfolgend alles als „histórico“ bezeichnet wird, was in der Historia de las Indias des Las Casas steht und in den Text Galváns übernommen wird: Fray Bartolomé ist historischer Gewährsmann dieses historischen Romans.

30 Ebda., S. 215. 
Damit erscheint der spanische Mönch und vielseitig Gebildete als das eigentliche Sprachrohr Gottes: Seine Texte und Worte sind Gottes Worte, die direkt in den Romantext Eingang finden. Kein Wunder, dass Enriquillo umgekehrt zu einer wahren Bibel der Dominikaner wurde! Der Erzählerdiskurs lässt ebenso wenig Zweifel daran, dass die Vorstellungen des Las Casas nicht nur damals, sondern auch noch heute, „en nuestro democrático siglo XIX“, von größter Aktualität sind. ${ }^{31}$ Es wäre sicherlich nicht übertrieben, wenn man Las Casas, dessen Beredsamkeit auch im berühmten historischen Streitgespräch vor Kaiser Karl V. vorgeführt wird, ${ }^{32}$ als den gar nicht so heimlichen eigentlichen Helden dieses Romans bezeichnete. Denn er ist die treibende geschichtliche Kraft dafür, die indigene Bevölkerung und Teile ihrer Kultur in die entstehenden transkulturellen Konstellationen der Karibik aufzunehmen.

Doch die Geschichte fügte es bekanntlich anders: Denn die Verbindung des ,protonationalen' Enriquillo konnte auch von Las Casas nicht zum guten, zum besseren Spanien ausfindig gemacht werden - eine Verbindung, die man im Übrigen sehr wohl in paternalistische Termini fassen könnte. Enriquillo war nicht umsonst von Las Casas getauft und mit seinem neuen Namen versehen worden, so wie die Insel selbst von den spanischen Eroberern einen neuen Namen erhielt. Im Gegensatz zu den Konquistadoren repräsentiert Las Casas aber die rein positive Seite der Eroberung: Er ist der gütige Vater, dessen Gestalt das Geschehen beherrscht und letztlich zu einem guten Ende führen will. Die Durchsetzung des katholischen Glaubens mit Feuer und Schwert sowie die Ausmerzung der indigenen Bevölkerung auf den Antilleninseln konnte jedoch auch er nicht verhindern. Der Roman geht freilich zu diesem entscheidenden Zeitpunkt in der Geschichte der Insel Hispaniola zurück.

Doch nehmen wir die Romanhandlung dort wieder auf, wo wir sie für einen Augenblick verlassen haben! In der spanischen Kolonie Hispaniola haben längst die Gegner der Familie des Christoph Kolumbus die Oberhand gewonnen. Sie versuchen, nicht nur ihn und seine Angehörigen persönlich zu beschädigen und von der Macht zu verdrängen, sondern auch all jene aus dem Weg zu räumen, die gegenüber der Logik der Conquista und der brutalen Unterdrückung sowie Ausplünderung der indigenen Bevölkerung kritische Einwände vortragen. Selbst gegenüber den aufmüpfigen Dominikanern verteidigen die unverkennbar als Schurken repräsentierten Spanier die Notwendigkeit, die Indianer auszubeuten, bringe man ihnen doch schließlich die wahre Religion und das Seelenheil von Christenmenschen. ${ }^{33}$

31 Ebda., S. 344.

32 Ebda., S. $345 \mathrm{ff}$.

33 Ebda., S. 232. 
Die Streitigkeiten werden erbittert geführt und bis an den spanischen Hof getragen. Das einstweilige Ergebnis sind die von Fray Antonio Montesino erwirkten und am 27. Dezember 1512 von König Ferdinand verkündeten Ordenanzas oder Leyes de Burgos, die den Indianern größere Rechte einräumen - eine „goldene Seite der Geschichte“, wie der Erzähler kommentiert. ${ }^{34}$ Der dominikanische Roman ist gerade in dieser Phase bestrebt, die historischen Hintergründe darzustellen und in das Romangeschehen zu verwickeln, wobei die Eroberung der Insel Kuba von Hispaniola aus einen gewissen Schwerpunkt darstellt. In diese historischen Ereignisse eingebettet wird die Geschichte Enriquillos insoweit vorangetrieben, als die ins Auge gefasste Hochzeit des herangewachsenen stattlichen Kaziken mit der schönen, gerade einmal fünfzehnjährigen Mencía heranrückt.

Dabei tut die Überraschung des künftigen Bräutigams wenig zur Sache, dass die Körperformen der jungen Frau nicht mehr denen jenes Kindes entsprechen, dessen Bild Enriquillo noch immer im Gedächtnis bewahrte. Die Ehe mit der Schönen ist von den Vertretern des ,Guten“ zwar sorgsam geplant, wird von denen des ,Bösen“ aber zunächst erfolgreich hintertrieben. In diesem Zusammenhang ist klar, dass Pedro de Mojica ${ }^{35}$ in diesem Spiel eine herausragende IntrigantenRolle zukommt: Für Enriquillo beginnt eine lange Kette von Erniedrigungen. Dank eines Briefes von Las Casas aus dem fernen Spanien können diese Vorkommnisse auf das Jahr 1515 datiert werden.

Die Liebe der unschuldigen und schüchternen indianischen Turteltauben, die in ihrer Arglosigkeit nicht zu lügen vermögen, wird letztlich den Sieg davontragen; das ahnen die Leserinnen und Leser, auch wenn diese Liebe den jungen Kaziken und die schöne Enkelin der Anacaona nicht zu einem lange währenden Glück führen kann. Erst ganz am Ende langer Seiten, auf welchen alle Demütigungen, die Enriquillo von den Spaniern erdulden muss, wortreich dargestellt werden, wird der junge Indianer nicht mehr den Gehorsam und das Bitten, sondern die Rebellion und den entschiedenen Widerstand wählen. Seine Autorität - die Indianer sind ihm als Erben der Macht, aber auch aus Liebe verpflichtet - und seine herausragenden Führungsqualitäten hatte Enriquillo schon zuvor unter Beweis gestellt. Unter dem jugendlichen Kaziken ist aus den indianischen Dörfern eine wahrhaft idyllische Landschaft mit funktionierenden landwirtschaftlichen Betrieben zur Herstellung landestypischer Produkte und „artesanías“ entstanden: Die Insel verwandelt sich unter seiner Hand zurück in einen klassischen Locus amoenus. Enriquillo selbst weiß, dass es eine Zeit der „grandes pruebas“,

34 Vgl. ebda., S. 237.

35 Ebda., S. 268. 
der schweren Prüfungen ist, die er durchlaufen muss. ${ }^{36}$ Erst danach ist er endgültig zum Mann, zum indigenen Helden gereift.

So ziehen nahezu vier Jahre ins Land. Wir gelangen in das Jahr 1519: Endlich kommt es zum Aufstand Enriquillos, der von seinen Gefährten, aber auch von seiner Frau Mencía, die einen wackeren Mann will, buchstäblich herbeigesehnt wird. Damit schließt sich der Kreis: Der mutige Enriquillo geht wieder in die Berge und tritt das rebellische Erbe des tapferen Guaroa an. Der Blick auf die Berge von Bahoruco, die tropisch-karibische Berglandschaft sagt alles: Dort allein ist Freiheit, dort allein lebt man weit entfernt vom kolonialen Joch der spanischen Herrschaft! Enriquillo wird in gewisser Weise zum „Cimarrón“, indem er sich etymologisch richtig - auf die „Cimas“, auf die Spitzen der Berge seiner Heimat wehrhaft zurückzieht.

Alles ist vorbereitet: Bei seinem Aufbruch in die Berge wird Enriquillo von seiner Frau Mencía begleitet, die standesgemäß in einer Sänfte getragen wird. Die Akklamation des jungen Helden zum aufständischen indigenen Führer ist eine Formsache. Schnell entstehen neue Gewohnheiten, zu denen freilich als Zeichen einer tiefgreifenden Transkulturation auch das von Enriquillo niemals vergessene Beten des Rosenkranzes gehört. Wie schon bei Chateaubriand bildet das Christentum auch in der Wildnis einen sicheren Hort des Geistes und der Seele: Enriquillo trägt immer wieder die Zeichen der Romantik und ist nicht von ungefähr stets von tiefer Melancholie erfasst. Und doch merkt man die Schule der Dominikaner bei diesem liebevoll rebellierenden Indio, der keinesfalls die christlich-abendländische Kulturtradition in Frage stellt, sondern im Gegenteil noch bei seinem Volk zu verbreiten hilft. In dieser Hinsicht erweist sich der Rebell zugleich - auch im Sinne Guaroas, der dies zu Beginn des Textes Higuemota vorgeworfen hatte - als kultureller Überläufer. Doch formulieren wir freundlicher: Enriquillo vertritt die in die Vergangenheit projizierte Utopie einer indigenen Gemeinschaft, die sich auf den Weg der Transkulturation begeben hat.

Der junge Mann erweist sich rasch als militärischer Stratege. Denn er schlägt in einer beeindruckenden Feldschlacht die Spanier, welche ihn und seine Leute siegessicher in die Berge verfolgten. Pedro de Mojica, der sich noch einmal retten kann, bringt er eine tiefe Wunde bei; doch der Spanier wird von Tamayo an einem Baum aufgeknüpft und damit als Inkarnation des Bösen seinem verdienten Ende zugeführt. Doch Enriquillo, der Edle Wilde, vergibt einem seiner ärgsten und unnachgiebigsten Widersacher, der im Übrigen auch ein Rivale um die Gunst der schönen Mencía ist, weil er das Andenken von dessen Vater ehren will.

36 Ebda., S. 373. 
So praktiziert der seelengute Kazike christliche Nächstenliebe und Demut: All dies zur Erbauung der auf ihn stolzen Indianer sowie der geschätzten Leserschaft des Romans. Wie einst der junge fränkische Held im Rolandslied, der Chanson de Roland, mit seinem berühmten Olifant gibt auch Enriquillo mit seinem „Caracol“, einem in indigenen Kulturen geheiligten und nur Männern vorbehaltenen Instrument, seiner Truppe befehle und bläst taktisch stets sicher zum Angriff oder wenn es sein muss - auch zum Rückzug. ${ }^{37}$

Alle Pläne und militärischen Versuche der Spanier, den Indianeraufstand im Blut zu ertränken, schlagen fehl. Enriquillo trotz seinen Widersachern dank seiner überlegenen Intelligenz. Und was tut der Held, wenn er nach getaner Arbeit müde nach Hause kommt? Dort wartet die huldvolle Dame seines Herzens auf ihn, ist Mencía doch nun endgültig von Liebe zu ihm entflammt, da sie stolz auf ihren Mann sein kann. Die Enkelin der schönen, mythischen Anacaona erweist sich ihrer Abkunft als würdig:

Eine Zeitlang zeigte sie sich besorgt und traurig; ihre Einsamkeit erschien ihr fürchterlich, während ihr geliebter Begleiter Enrique sich gänzlich der Organisation und Verteidigung seines gebirgigen Staates widmete. Aber als der tapfere Kazike sich ihren Augen zum ersten Male als Sieger präsentierte; als er ihr das unnütz gewordene Schwert des arroganten Valenzuela zu Füßen warf; als er sich ihr noch ganz vom Staube des Kampfes bedeckt in seiner Größe und wahrhaftig frei, in der hehren Aureole des heroischen Mutes und der wiedererlangten Würde zeigte, da schlug das Herz von Mencía, erfüllt von höchster Befriedigung und legitimem Stolze, höher und schneller, und so warf sie sich in die Arme des tief bewegten Kriegers, küsste mit heiligem Enthusiasmus sein männliches Gesicht; und kristallklare Tränen rannen über den starken und staubigen Hals des Caudillo, und seine vor erfreuter Bewegtheit erzitternden Lippen murmelten kaum hörbar diesen ausdrucksvollen Satz: Groß, frei und gerächt ...; so will, so liebe ich Dich! $!^{38}$

Gewiss, ich räume es gerne ein: Diese heroischen Zeilen sind uns heute etwas fremd geworden, der pathetische Klang dieser Sätze hat es schwer, uns noch zu bewegen! Doch die Zeitgenossen von Manuel de Jesús Galván waren tief bewegt ob solcher Expressivität und liebten das Pathos, mit dem sich ihnen ein indigener, nein, ein dominikanischer Held im christlichen Heiligenschein zeigte.

Enriquillo ist Indianer, mehr noch: ein Edler Wilder; doch von kultureller Alterität findet sich in diesen Passagen keine Spur. Hier haben wir jenes Paar vor uns, wie es in Gertrudis Gómez de Avellanedas Roman Sab so gerne von Carlota zusammen mit Enrique (Otway wohlgemerkt) gebildet worden wäre: gemeinsam einsam, einfach glücklich. Bis hierher reichen die Spuren von Chateaubriands

37 Ebda., S. 439.

38 Ebda., S. $456 \mathrm{f}$. 
Atala - und vielleicht auch weiter, bis zu Karl May und nach Bad Segeberg. Die Edle Wilde als tiefgläubige Christin natürlich in einem Berggebiet, umgeben von exotisch-subtropischer oder tropischer Natur: eine echte indianistische Prinzessin zum Greifen nahe und doch Jahrhunderte fern! Zusammen mit Enriquillo bildet sie eine ideale nationale Identifikationsfläche für die sich damals im Nationenbildungsprozess befindliche Dominikanische Republik.

Der Indianismus erweist sich spätestens an dieser Stelle als Mystifikation europäischer Provenienz unter Rückgriff auf Stereotype, die vor allem das 18. Jahrhundert in Umlauf gesetzt hatte. Immerhin dürfen wir feststellen, dass es Manuel de Jesús Galván mit seinem Enriquillo gelungen ist, die indigene Frage innerhalb der lateinamerikanischen Literaturen $\mathrm{zu}$ einer kulturellen sowie $\mathrm{zu}$ einer politischen zu machen und nicht länger - wie etwa im Cono Sur - gänzlich und vollständig aus den politischen und literarischen Diskussionen, bei gleichzeitig fortschreitendem Genozid an den Indianern zu verdrängen.

Dass auch eine andere Indianerin, subaltern zwar, ebenfalls Enriquillo liebte, habe ich in Zusammenhang mit der Liebe Mencías noch nicht erwähnt. Doch diese Liebe einer Frau, die es vom Rang nicht mit einer Enkelin von Anacaona aufnehmen kann, zählt schon bald nicht mehr: Sie muss sich fortan in Liebesverzicht und der Sublimierung ihrer Libido üben, die sich künftig in eine große Zärtlichkeit für Mencía verwandelt. Bald schon wird sie sich in die Ehe mit einem Enriquillo untergebenen Kaziken flüchten. In der Welt edler indianischer Gefühle, anders als in der brutalen europäischen Welt sexueller Forderungen und Vergewaltigungen an Seele und Leib, geht die Seelen- und Gefühlswelt in der Summe auf: Glückliches Arkadien, indianistisch gewendet!

Kein Wunder also, dass Enriquillo ganze dreizehn Jahre in glücklicher Rebellion verbringen kann, hat er sich doch eine eigene Republik, gleichsam einen „Palenque“ in den Bergen aufgebaut, der von den Spaniern nicht erobert werden kann. Bis zu dem Zeitpunkt, als ein Brief des deutschen Kaisers Karl V. und spanischen Monarchen Carlos I bei Enriquillo eingeht mit dem Ziele, gleichsam von Monarch zu Monarch Frieden zu stiften. ${ }^{39}$ Nach Abschluss der glanzvollen Übereinkunft bricht allgemeine Freude über den Friedensschluss zwischen dem europäischen Monarchen und dem indianischen Don Enrique aus - eine Freude, die von Bartolomé de Las Casas geteilt wird.

So ist es letzterer, der Enriquillo davon überzeugt, aus dem Gebirge der Insel Hispaniola in die Gemeinschaft aller zurückzukehren. Natürlich geschieht all dies zum höheren Ruhme Gottes: Selbst der wilde Tamayo wird getauft und damit der christlichen Gemeinschaft einverleibt; eines jener Ereignisse, die laut Fußnote des

39 Ebda., S. 470. 
Erzählers als historisch einzustufen sind. Die Fusion ist erreicht, die nationale Identifikationsfigur endgültig geschaffen, und so kann Enriquillo ein letztes Mal in der Sierra beruhigt vor dem Grabmal Guaroas beten. Die Rebellion ist zu Ende: Eine Revolution wie im anderen Teil Hispaniolas ist nicht daraus geworden.

Von den Seinen geliebt und den Spaniern respektiert, kann Enriquillo bald schon, nachdem er sein eigenes Dorf gegründet hat, in Frieden sterben. Die Zukunft gehört den Spaniern, die Vergangenheit aber - und diese ist identitätsstiftend - den guten, den edlen Indianern. ${ }^{40}$ Schauen wir auf das Ende, den letzten Abschnitt des dominikanischen Romans:

Dieser Name lebt und wird ewig leben: ein großer See wird ihn mit seiner geographischen Bezeichnung fortschreiben; die hohen Berge des Bahoruco scheinen ihn bis in die Region der Wolken emporzuheben, und die kurvenreiche Kordillere, die sich aus welcher Distanz auch immer in ihrer ganzen Weite wahrnehmen lässt, wird ihre hohen Spitzen in das Himmelsblau recken und die weit entfernten Horizonte konturieren, und alles wird mit schweigender Beredsamkeit von der glorreichen Erinnerung an diesen einen sprechen, Enriquillo. ${ }^{41}$

Der dominikanischen Landschaft ist der Name Enriquillos auf vielfache Weise eingeschrieben. Nicht nur die geographischen Karten, sondern auch identitäre Mappings tragen den Namen jener großen indianischen Gestalt: Enriquillo forever!

Varela Jácome hat Manuel de Jesús Galváns Enriquillo als den Höhepunkt des Historischen Romans in Hispanoamerika bezeichnet. ${ }^{42}$ Sein etwas großzügiges Lob bezieht sich insbesondere auf die historischen Ereignisse, die insgesamt objektiv dargestellt worden seien. Vor allem beeindruckte den spanischen Literaturwissenschaftler die sachkundige Verwendung historischer Quellentexte, welche teilweise auch aus dem Archivo de Indias stammten. Ob man freilich die historizistische Attitüde Galváns mit historischer Objektivität gleichsetzen darf, bleibt mehr als fraglich. Aber dies war auch nicht das vorrangige Ziel des dominikanischen Autors, der vielmehr eine nationale Allegorese für den Nationenbildungsprozess seiner Heimatinsel schaffen wollte.

Benito Varela Jácome hat jedoch mit Recht auf die nationalistische Komponente des Freiheitskampfes der Indianer hingewiesen, die innerhalb der Diegese des Historischen Romans den Spaniern ja nicht unterliegen, sondern diese zu einem ehrenvollen Frieden zwingen. Genau hierin ist es dem dominikanischen Schriftsteller gelungen, diese nationale Fragestellung - unter Umgehung und Ausklammerung der Schwarzen und Mulatten seines Landes - zum Ursprung

40 Ebda., S. 474.

41 Ebda.

42 Vgl. Varela Jácome, Benito: Evolución de la novela Hispanoamericana en el XIX, S. 103. 
und Ausgangspunkt nationaler Identität zu machen. Dass der schwarze Anteil an der dominikanischen Bevölkerung in diesem Konzept nicht zum Tragen kam, sondern ausgeschlossen wurde, hat nichts mit den historischen Entwicklungen, sondern mit der politischen Abgrenzung der Dominikanischen Republik vom ungeliebten Nachbarland Haiti zu tun.

In Manuel de Jesús Galváns Roman Enriquillo werden einmal mehr und auf sehr erfolgreiche Weise grundlegende Entwicklungstendenzen der spanischsprachigen karibischen Literatur eingefangen. Wir können an dieser Stelle unserer Vorlesung durchaus feststellen, dass die Karibik als Brennspiegel weltumspannender Globalisierungsprozesse und Zone verdichteter Globalisierung eine kulturelle Vielfalt bereithält, welche es nicht überall in Lateinamerika zu bewundern gibt. Kommen wir nun zum letzten Text unserer karibischen Serie: La Peregrinación de Bayoán des Puerto-Ricaners Eugenio María de Hostos, um damit unsere vielperspektivische Beleuchtung der Area der Karibik zu einem Ende zu führen! 